INFLUENCE OF PUBERTAL DEVELOPMENT ON THEOPHYLLINE KINETICS. Karen HeIn; Ralph Dell; Nancy Reuben; 13 Stephanle Ulrich. Departments of Pediatrics, Albert EInsteln College of Medicine and Columbia Untversity, College of P\&S, Bronx Mun

Theophylline half-life (HL) doubles between childhood and adulthood. Effects of pubertal changes on HL was studied to investigate dose changes required in adolescence.

Seventy asthmatics taking theophylline chronically were studied: in 48 patients, HL was determined from 3 serum levels $(8,10,12 \mathrm{hrs}$ after dose) and in $22, \mathrm{HL}$, volume of distribution (Vda) and clearance were computed from 21 timed levels over 24 hours. Age (8-18), Tanner stage (I-V), sex, helght $(121-182 \mathrm{~cm})$, welght $(23-83 \mathrm{~kg})$ and skin fold thicknesses $(3.6-36.3 \mathrm{~mm})$ were recorded. Growth variables (height \& weight velocity \& lean body mass) were derived from anthropometric measurements. Stepwise multiple regression analysis was performed with HL as dependent varlable. Half-life was significantly related ( $p<0.01$ ) to developmental stage (Tanner $r=0.42$, and age $r=0.33$ ) and body size (height $r=0.39$, LBM $r=0.33$, welght $r=0.31$ ). LBM $(\mathrm{kg} / \mathrm{kg}$ ) calculated by Lohman equation and $\mathrm{Vda}(1 / \mathrm{kg})$ were related $(x=0.59 ; p<.01)$. Best equations for $\mathrm{HL}$ contained 2 variables and were: (for sex, $\sigma^{t}=0$ and $q=1$ ).

$\mathrm{HL}=4.57+1.31 \mathrm{sex}+0.0687$ height $(r=0.48)$

$\mathrm{HL}=3.54+1.32 \mathrm{sex}+0.0725$ LBM $(r=0.43)$

Thus, half-1ife is related to age, sex and body size during adolescence. The dose and dosing interval must be monitored closely during adolescence because metabolic rate (HL) and body composition (Vda) both change rapidly during the teenage years.

\section{PREDICTING AEROBIC CAPACITY IN ADOLESCENTS}

Albert $C$. Hergenroeder and Robert Schoene

14 The purpose of this study was to develop regression equations to predict $\left(\mathrm{VO}_{2}\right)$ max and $\left(\mathrm{V}_{2} / \mathrm{kg}\right)$ max in a cross section of normal, not pre-selected adoles-

cents. Forty students had $\left(\mathrm{VO}_{2}\right)$ max measured on a cycle ergometer. Age, sex, height, weight, percentage of body fat (estimated), thigh circumference, and anterior thigh skin fold were measured. Sexual maturity rating was estimated using the method of Duke and performance on the 12 minute and 1.5 mile runs was recorded. Of the run performances, 1.5 mile run speed had the highest correlation with $\left(V_{2}\right) \max (r=0.57)$ and $\left(V_{2} / \mathrm{kg}\right)$ $\max (r=0.72)$. Of all variables, height had the highest correlation with $\left(V_{2}\right) \max (r=0.79)$. Using multiple stepwise regression analysis, equations were developed to predict ( $\mathrm{VO}_{2}$ ) $\max$ and $\left(\mathrm{VO}_{2} / \mathrm{kg}\right.$ ) max: $\left(\mathrm{VO}_{2}\right)$ max (liters/min) $=-0.56926 \times 10^{-2}$

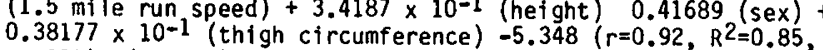
$\mathrm{p}<.001) .\left(\mathrm{VO}_{2} / \mathrm{kg}\right) \max (\mathrm{cc} / \mathrm{kg} / \mathrm{min})=0.13499$ ( $1.5 \mathrm{mile}$ run speed) -2.3233 (age) -5.3145 (sex) $+59.39\left(r=0.82, R^{2}=0.67, p<.001\right)$. Estimated sexual maturity rating did not contribute significantly to the variance. These equations were cross validated six months later when all runs and measurements were repeated

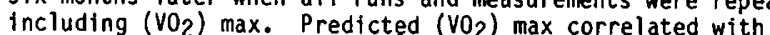
measured $\left(\mathrm{V}_{2}\right) \max \left(r=0.92, R^{2}=0.85, p=10^{-5}\right)$ and predicted $\left(\mathrm{V}_{2} / \mathrm{kg}\right)$ max correlated with measured $\left(\mathrm{V}_{2} / \mathrm{kg}\right) \max (r=0.76$, $\left.R^{2}=0.58, p=10^{-5}\right)$. These results suggest regression equations which can accurately estimate $\left(\mathrm{V}_{2}\right) \max$ and $(\mathrm{VO} / \mathrm{kg})$ max in a cross section of normal adolescents.

ABUSE AND HEALTH BEHAVIORS IN A STUDENT +15 Population, Roberta A. Hibbard, Catby Brack. Denald P.orr, Indiana Univ. Dept. of Pediatrics, Indianapolis, IN.

Behavioral oquellae of child abuse are frequently noted, however, there are few studies of nonclinical children examining the otrength of such associations. As part of a health needsassessment, we surveyed 712 junior high students ( 7 th- 9 th grade, mean age 13.5 years) for olf-reports of abusive experiences and health behaviors. The sample was $50 \%$ male, 77\% white and represented all socioeconomic levelo. $18.3 \%$ students reported physical (PA) andor sexual abuae (SA); $14.7 \%$ reported $P A, 8.1 \%$ reported $S A$ and 4.17 reported both. Reports did not differ by age or race, but more females (12.6\%) than males $(3.97)$ reported SA $\left(p=0.0, x^{2}\right)$. Both PA and SA were asoociated with running away, considering hurting oneself, suicide attempts, and the use of drugs, pot, alcohol, cigarettes, and iaxatives (all p<.01). strength of asociations (odds ratios) range from 1.8 for the risk of alcohol use to 4.7 for the risk of running away. No clinically significant

relationships were found between SA/PA and anger, sadness or self-esteem. This data confirms some previous reports and indicates the need for studies of nonclinical populations.
INFANTS OF ADOLESCENTS: PREDICTING DEVELOPMENT AT FOUR YEARS FROM PERINATAL HEALTH STATUS, EARLY INTERACTION, AND

16 SOCIAL RISK J. A. Hofheimer, Frank Porter Graham Child Development Center, UNC at Chapel Hill, A. B. Packer, Univ. of Florida, \& K. E. O'Grody. (Spon. by E.
E. Lowson).

This study examined 6-48 month development in infants born to 31 low SES young adolescents (YA; $14-17$ yrs.), 18 older odolescents (OA; 1819 yrs.), 15 adults (LA; 20-38 years), and 25 higher SES adults (HA). Perinatal risk (Habel) was assessed, the Bayley administered ot 6 \& 24 months, and Kent language, cognitive, social, gross and fine motor subscales colculated; the McCarthy was administered at 48 mos. Motherinfant interaction during unstructured play was videotaped and coded using Beckwith's measures and the Toddler GLOS at $6 . \& 24$ months, respectively. An index of social risk at 6 mos. was derived from demographic interviews. Hierarchical multiple regression analyses indicated ( $p$ 's <.05) that at each age, higher scores on the Bayley cognitive and language subscales \& the McCarthy were associated with lower social \& perinatal risk, with more focilitative interaction patterns $\&$ maternal vocalizations. Infants of YAs had lower scores on many subscales. During interaction, adolescents were more aversive at 6 months, and more controlling and less responsive at 24 months. The data suggest the early and persistent influences of odolescent motherhood which are exacerbated by social and perinatal risk on developmental outcomes for infants.

\section{+17 University of Cal ifornia, San Francisco, Department of Pediatrics, San Francisco}

In spite of adolescents' knowledge about health damaging effects of alcohol, they continue to initiate alcohol use at high rates. This study was designed to investigate early adoliescents' expectations of positive and negative effects from alcohol use on four domains in their life: physical health, social life, functional ability and self concept. It was hypothesized that early adolescents would view the effects of alcohol on their physical health differently than its effects on their social life, function, and self concept. 593 ethnically diverse adolescents attending a middle school completed the study protocol $\bar{X}=13 y$ rs; S. $D_{0}=94$ ). 518 of sample was female. Subjects did not judge the potential effects of alcohol equally across the four domains ( $p<.001$ ). Alcohol was perceived as being most likely to have a negative effect on physical health and least likely to have a negative effect on one's social life. positive effects of alcohol use were viewed as most likely in the social arena. The degree to which adolescents made differential judgements across life domains varied as a function of drinking status; drinking experience was associated with greater differentiation ( $p<.001$ ). The effects of drinking on social life were most strongly associated with intentions of drinking in the next year $(p<.001)$. Adolescents who intended to initiate drinking in the next year endorsed alcohol as most likely to have a positive effect on their self concept. Results suggest the need to focus on domains other than physical health in the development of programs for early adolescents in decisions regarding alcohol use.

ADOLESCENTS' COMPLIANCE WITH MENTAL HEALTH REFFERALS. Leslie Jaffe, Richard Wortman, Argela Diaz, Sanford 18 Melzex, Lorena Siqueira and Annie Steinberg (Spon. Mount Sinai Sch. of Med., New York, N.Y.

The purpose of this study was to elucidate factors which contribute to adolescents' compliance with mental health referrals. Fifty-seven Black and Hispanic inner-city youth ages 11-20 (meanm 16.1), attending a comprehensive adolescent health clinic, were referred by 5 primary care physicians for counseling services. At the time of referral, both the physician and patient completed questionnaires; the patient's questionnaire included the children's Depression Inventory (CDI). Initial counseling appointments were kept (compliance) by 43.18 (24) of the patients. Females were significantly more compliant (2l of 42) than males ( 3 of 15$)\left(x^{2}=4.08 ; p<.05\right)$. While all but two patients saw themselves as having problems, those who vlewed their difficulties as more serious ("big problems") were less likely to keep appointments ( 6 of 21 ) than those who described themselves as having "small problems" (18 of 33$)\left(x^{2}=3.5 ; p<.10\right)$. Compliance was not affected by whether the patient saw the referral as his decision or one made jointly. The degree of the family's involvement and attitude towards counseling did not affect compliance. The degree of depression as determined by the CDI was not slgnificantly different between compliers and noncompliers. We conclude that, while identification of patients likely to comply with mental health referrals is not possible, physicians should be on the alert for those patients who feel overwhelmed by their problems. In most need of help, these may be the very patients who do not avail themselves of mental health services. 